\title{
THE 4DILAN PROJECT (4TH DIMENSION IN LANDSCAPE AND ARTIFACTS ANALYSES)
}

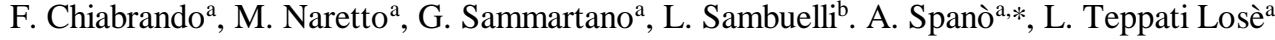 \\ ${ }^{a}$ Politecnico di Torino, DAD, 10129, Torino, Italy - (filiberto.chiabrando, monica.naretto, giulia.sammartano, antonia.spano, lorenzo \\ teppati)@polito.it \\ b Politecnico di Torino, DIATI, 10129, Torino, Italy - (luigi sambuelli@polito.it)
}

\section{WG V/1, WG V/2, WG II/8 WG IV/2}

KEY WORDS: 3D modelling, UAV photogrammetry, GPR (Ground Penetrating Radar), TLS (Terrestrial laser scanning), archive documents, knowledge for conservation project

\begin{abstract}
:
The project is part of the wider application and subsequent spread of innovative digital technologies involving robotic systems. Modern society needs knowledge and investigation of the environment and of the related built landscape; therefore it increasingly requires new types of information. The goal can be achieved through the innovative integration of methods to set new analysis strategies for the knowledge of the built heritage and cultural landscape.

The experimental cooperation between different disciplines and the related tools and techniques, which this work suggests for the analysis of the architectural heritage and the historical territory, are the following:

- $\quad 3 \mathrm{D}$ metric survey techniques with active and passive sensors - the latter operating in both terrestrial mode and by aerial point of view. In some circumstances, beyond the use of terrestrial LiDAR, even the newest mobile mapping system using SLAM technology (simultaneous localization and mapping) has been tested.

- Techniques of non-destructive investigation, such as geophysical analysis of the subsoil and built structures, in particular GPR (Ground Penetrating Radar) techniques.

- Historic and stratigraphic surveys carried out primarily through the study and interpretation of documentary sources, cartography and historical iconography, closely related to the existing data or latent material.

The experience through the application of these techniques of investigation connected to the built spaces and to the manmade environments has been achieved with the aim of improving the ability to analyse the occurred transformations/layers over time and no longer directly readable or interpretable on manufactured evidence.
\end{abstract}

\section{INTRODUCTION}

The reconstruction of the history of a building, prior to any project of conservation, recovery, restoration treatment is an accepted and well-established starting point of modern approaches to preservation of cultural heritage $(\mathrm{CH})$. (ICOMOS charters and other doctrinal texts http://www.icomos.org/en/charters-and-texts)

The different disciplines responded by developing different techniques and refining methods to respond to this great basic requirement. In general terms, the surveying techniques, even before the establishment of Geomatics, which today includes the oldest sciences of land, built heritage and any kind of other $\mathrm{CH}$ surveying, based in the past the possibility of reconstructing the building palimpsest relying on Architectural Photogrammetry. The images in fact set in a storable document the situation of the moment of the shot.

The possibilities provided today by the use of integrated Structure from Motion (SfM) technique in photogrammetric process, together with the dense clouds production algorithms, have provided the possibility to exploit the technological evolution, which integrates the auto-calibration of the cameras in the block orientation processing, to develop exponentially the ability of using archive images even distant in time. (Sammartano et al., 2017)

To stay longer in the field of heritage documentation using image-based techniques, we are witnessing today the development of theoretical studies that aim to specialize SfM technique to get reconstructive models even in critical scenarios (Cohen et al., 2015). Another emerging field of study and applications aims to reconstruct lost $\mathrm{CH}$ caused by wars or natural disasters, even exploiting crowdsourcing strategies. (Stathopoulou et al., 2015, Bashar 2016)

The present research purpose indeed, aims to give emphasis to analytical skills related to the time dimension of individual techniques and different methods: geophisical investigations and documentary sources reading, in connection to survey techniques. The goal is taking advantage of the broader integrated multidisciplinary comparison with their interaction and collaboration. (Sambuelli et al., 2015; Arato et al. 2016, Di Pietra et al., 2017)

A method of inquiry that has become virtually an independent discipline is known in italian area Architecture Archeology (Brogiolo, Cagnana, 2012). In this field of study, the use of archaeological methods in the study of architecture aims to enrich the knowledge base, since buildings show signs of transformation, restoration, reconstruction, and demolition.

\footnotetext{
* Corresponding author
} 
The application of the stratigraphic method to archaeology hails from Edward Harris' experiences dating back to the midtwentieth century (Harris 1989). The goal is to define construction phases of the building (chronological sequences) within a relative chronology and subsequently, their settings in an absolute chronology introducing dates or periods.

The project of integrating these survey techniques was called 4Dilan ( $4^{\text {th }}$ dimension in landscape and artifacts analyses); all the activities were developed according to another key point that was connected to the educational purpose. Consequently, all the preliminary studies, the data acquisition on the field, data processing and the final interpretation of the results were carried out with the active involvement of groups of students. This objective was pursued to improve the knowledge of the involved students in order to become acquainted with different disciplines and face with different experiences that are not usually provided in the normal educational path of the areas of Engineering and Architecture. Moreover, this approach develops the experience of the students increasing the competence regarding the interdisciplinary data management to support decisions, as well as to design interventions in the field of Cultural Heritage.

The paper deals with two applications of the proposed methodology in the Piedmont area. The first test has been realized in the area of the Novalesa abbey, a built complex with extraordinary landscape and architectural richness

The second case study is the castle of Valperga overlooking a little village at $50 \mathrm{~km}$ from Torino. The castle was built in a strategic position, on the top of the hill around which, afterwards, the settlement of Valperga was based on a semi-circular shape.

\section{METHODS}

\subsection{Geomatics techniques}

Among the many developmental perspectives of survey methods, the one that is largely of wider interest in some years is the use of UAV (unamanned aerial vehicle) photogrammetry. By acquiring images at low altitudes and being able to effectively target the object being investigated by nadiral and oblique images, it provides a clear strength in the context of the documentation of CH. (Wiedemann et al. 2012, Remondino et al. 2011).

Among the most investigated aspects there is certainly the integration with terrestrial data, often of Lidar nature, to generate multiscale and multisensor 3Dmodels, orthophotos and other useful graphical 2D/3D products. (Lerma et al., 2011)

Another of the features that are particularly attractive in the field of heritage documentation is the low cost of the techniques and their expediency, which makes the process of generation the dense and rich information 3D models particularly sustainable in the overall preservation plan.

These cited approaches have also been used in the perspective of the 4Dilan project, and in one of the applications, the innovative 3D mobile mapping system, the hand-held Zeb Revo system by Geoslam. (http://geoslam.com/) has been experimented.

This system exploit a 2D lightweight time-of-flight scanner with $30 \mathrm{~m}$ maximum range (Hokuyo scanner) and an Inertial Measurement Unit (IMU), which ensure roughly the position of the device during the moving acquiring session. The continuous revolution movement of laser sensor generates the $3 \mathrm{D}$ point cloud and the mapping system is based on the Simultaneous Localization and Mapping (SLAM) technology (Bosse, Zlot, Flick, 2012). The innovative aspect of this technology is the chance to use the environment to update the position of the device (Riisgaard, Blas, 2005).
The raw trajectory enable to roughly calculate the surface normals and potential constraints (features recognition) within a single sweep of the scanner. Then a cloud-to-cloud registration generate the $3 \mathrm{D}$ cloud using an iterative process which relies on geometric objects and features within the constrains, essential to align subsequent scans.

\subsection{GPR (Ground Penetrating Radar) technique}

The GPR method is based on sending an electromagnetic (EM) impulse by a transmitting antenna (Tx) and receiving the echoes by a receiving antenna (Rx). The commercial GPR systems work in the frequency range between $10 \mathrm{MHz}$ and $3 \mathrm{GHz}$. The choice of the system frequency is essential and has to be made according to a trade-off between penetration depth and resolution. In fact, the earth material act as low pass filters with respect to the EM waves. This means that lower frequencies (i.e. long wavelengths) may go deeper in the subsoil than higher frequencies (i.e. short wavelengths). Then, in principle, we should use low frequencies to get higher penetration depths. On the other hand the resolution, that is the capability to show small objects, depends on the wavelength: the shorter the wavelength, the better the resolution. In other words lower frequencies imply deeper signal penetration but lower resolution, while higher frequency allow higher resolution but lower signal penetration.

In archaeological surveys, GPR is used to find the interfaces between the soil and the buried structures. Soil characteristics (porosity, texture, mineral composition, pore-fluid distribution and chemistry) determine the soil EM impedance (Zem), which is very often different from the one of the material the buried structures are made of. The electromagnetic discontinuities (or dielectric interfaces) between two media with different Zem, in fact, act as signal reflectors, refractors and diffractors (e.g. Davis and Annan, 1989; Reynolds, 1997). Common GPR surveys are carried out by moving the antennas along parallel profiles on the $\mathrm{x}-\mathrm{y}$ plane to obtain, pulling together the echoes (i.e. the radar traces), the radargram. This latter is an image which has on the horizontal axis the running positions of the antenna ( $\mathrm{x}$ ) and on the vertical axis the so called two-way-traveltime (twt) that is the time the impulse takes to travel down and up in the subsoil. Within the radargrams the echoes which come from different depths along the profile and hence the underground electromagnetic interfaces can be identified. Knowing the propagation velocity of the EM impulse in the soil the radargrams can be transformed, via the simple relation $\mathrm{z}=\mathrm{v} \cdot 0.5 \cdot \mathrm{twt}$ in vertical EM sections ( $\mathrm{x}-\mathrm{z}$ plane) of the subsoil below the profiles. Usually in the archaeological surveys the analysis of many single parallel radargrams is not meaningful. Much more significant are the so called time-slices (or depthslices) obtained by properly assembling in the space the radargrams, in a so called data-cube, and extracting horizontal cuts that are images on the planes x-y at different times (twt) or depths (z).

\section{THE EXERIENCES}

\subsection{First case study: Novalesa Abbey (Piedmont - Italy)}

The Gallo-Roman rector Abbone, belonging to a prominent family of the Merovingian aristocracy, founded the Benedictine abbey of Novalesa, dedicated to the saints Peter and Andrea, on January 30th 736 A.D. It is, in fact, one of the oldest and important abbeys of the whole Alpine arch, placed in a strategic area for the frank advance towards the Po Valley.

Its multi-century history is well-known, thanks to the long series of archaeological investigations, begun in 1978. The data until 
now acquired allow a preliminary reconstruction of the main phases of the monastic complex and its transformations over the centuries, but much remains to be discovered.

For example, the relationship between the chapels around the central core of the monastic complex and the core itself is not clear. Moreover, historical cartography tells us that the access was different from the present one and other documentary sources, such as the archaeological excavations of the Chapel of Santa Maria, tell us that this chapel was placed in a probable area of welcome of pilgrims.

The attempt to clarify on this point was the focus of the 4dilan project's use and comparison of investigating techniques.

\subsubsection{Image and range based integrated surveys and historical cartography}

Considering the purpose of investigating a problem of spatial, functional and temporal relations between the different artefacts of the abbey, the approach could only be based on a comparison between a large scale map of the complex, which was built by UAV photogrammetry, and historical cartography.

Observing the map of figure 1 (second half of the eighteenth century), superimposed to the regional technical map, we can see that the ancient access way was to the west of the current, till today coded as rural road. A second road, crossing the creek Cenischia, downstream of the current bridge that allows access from the center of Novalesa built-up area, is even visible (only in the map, as we are going to see in the next UAV orthophoto). In Novalesa we made numerous flights using two different platforms and different flight strategies (Aicardi et al., 2016), but in this paper we will refer only the executed flight using the eBee autonomous flying drone bt SenseFly Company, marketed by Menci Software https://www.sensefly.com/drones/eBee.html), which made possible to realize the DSM and orthophoto at a smaller scale.

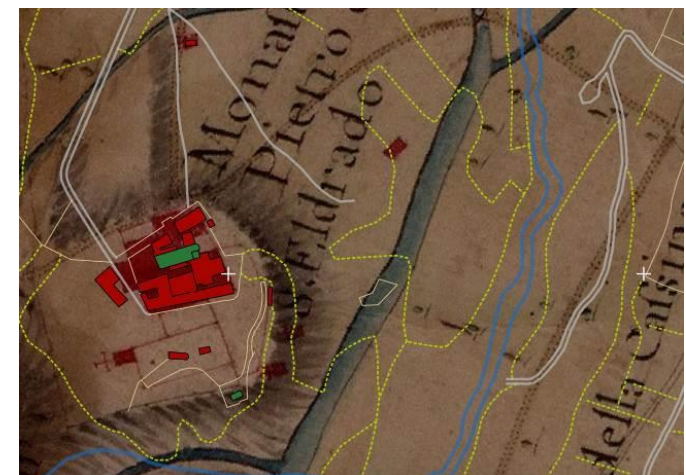

Figure 1. Old Cartography for the analysis of the Abbey's territory superimposed to the regional technical map [The great map of the Susa Valley. AST, Court, Topographic maps and drawings, Topographic maps for A and B, "Susa 3"]

\begin{tabular}{|l|l|}
\hline camera: & Canon PowerShot S110 \\
\hline number of acquired images: & 417 \\
\hline image dimension & $\begin{array}{l}4000 \quad \text { [pixels] x } 3000 \\
\text { [pixels] }\end{array}$ \\
\hline sensor dimension & $7.440[\mathrm{~mm}]$ x 5.580 [mm] \\
\hline Ground sampling distance & $5.06[\mathrm{~cm}]$ \\
\hline focal distance: & $5.2[\mathrm{~mm}]$ \\
\hline flight height (medium) & $141.4624[\mathrm{~m}]$ \\
\hline $\begin{array}{l}\text { RMS error (Root Mean Square } \\
\text { error): }\end{array}$ & $0.004[\mathrm{~m}]$ \\
\hline
\end{tabular}

Table 1 - Camera and Ebee flight parameters
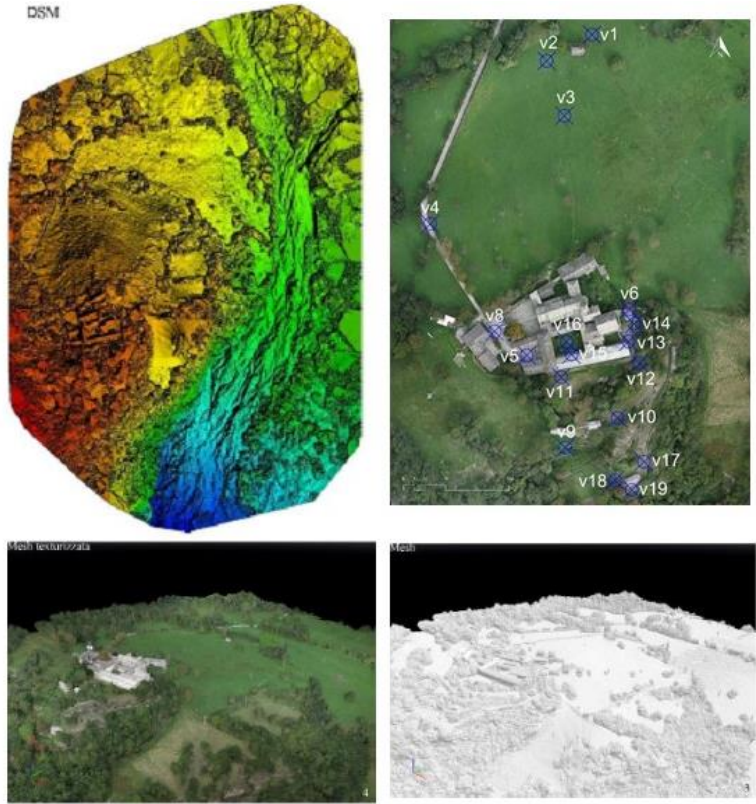

Figure 2. (Above left) Digital Surface model processed by Pix4Dmapper software. (Above right) Topographical network; (below) meshed model and textured meshed model. (Patrucco, 2016)

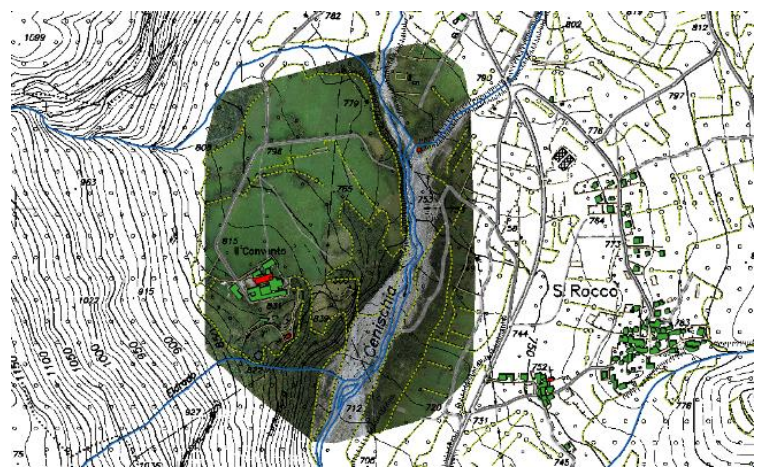

Figure 3. Estension of orthophoto compared with regional map.

The flight has been performed according to the parameters reported in table 1 and having previously measured 52 plane targets with GPS / RTK technique, obviously connected to a topographical network of vertices determined also with satellite technique GPS / GNSS.

The first material sign of a past configuration today no longer appreciable, which is the access route that laps the Santa Maria chapel, has been investigated with the GPR technique, reported in the next paragraph 3.1-2. After a series of inspections that have been completed along the shores of the stream, the bridge on Cenischia, though only slightly visible on the orthophoto (Figure 3), has been identified and detected with the LiDAR technique (Figure 4). Documentary sources report that the access road was used by the Savoy court on visit to the abbey.

\subsubsection{GPR investigations on entrance areas}

Acquisition and processing, and results.

The survey was made on September 23, 2015 with a K2 IDS GPR and a $200 \mathrm{MHz}$ IDS antenna. The GPR profiles were acquired along two perpendicular directions: $\mathrm{N} 65^{\circ} \mathrm{E}(\mathrm{x})$ and $\mathrm{N} 25^{\circ} \mathrm{W}(\mathrm{y})$. The $\mathrm{x}$ profiles were 21 , spaced $1 \mathrm{~m}$ and $50 \mathrm{~m}$ long 


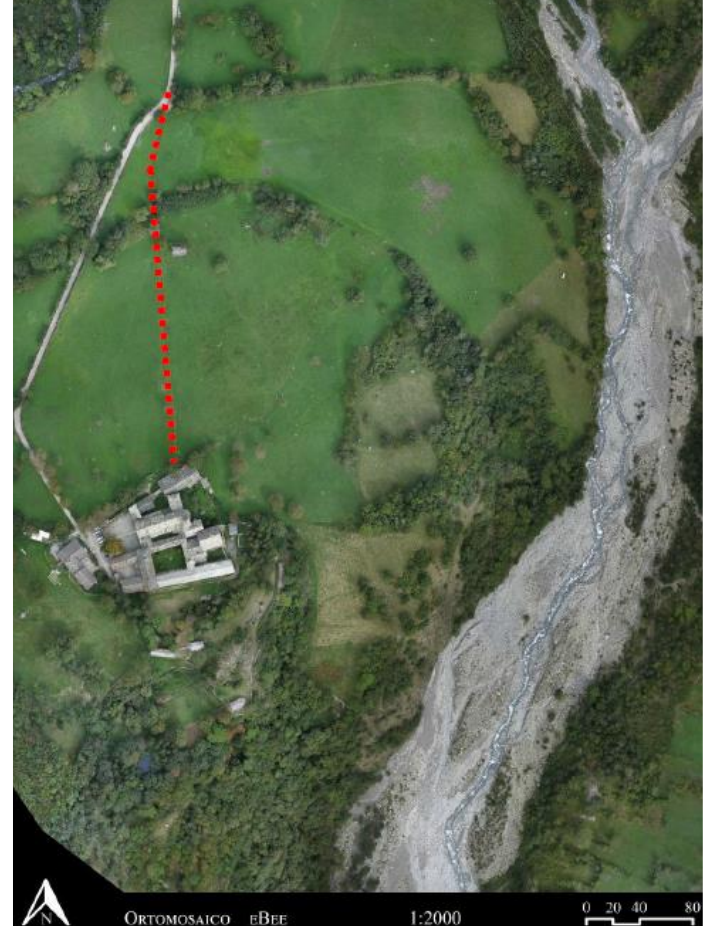

Figure 4. 1:2000 scale orthomap with the ancient access route highlighted in red.

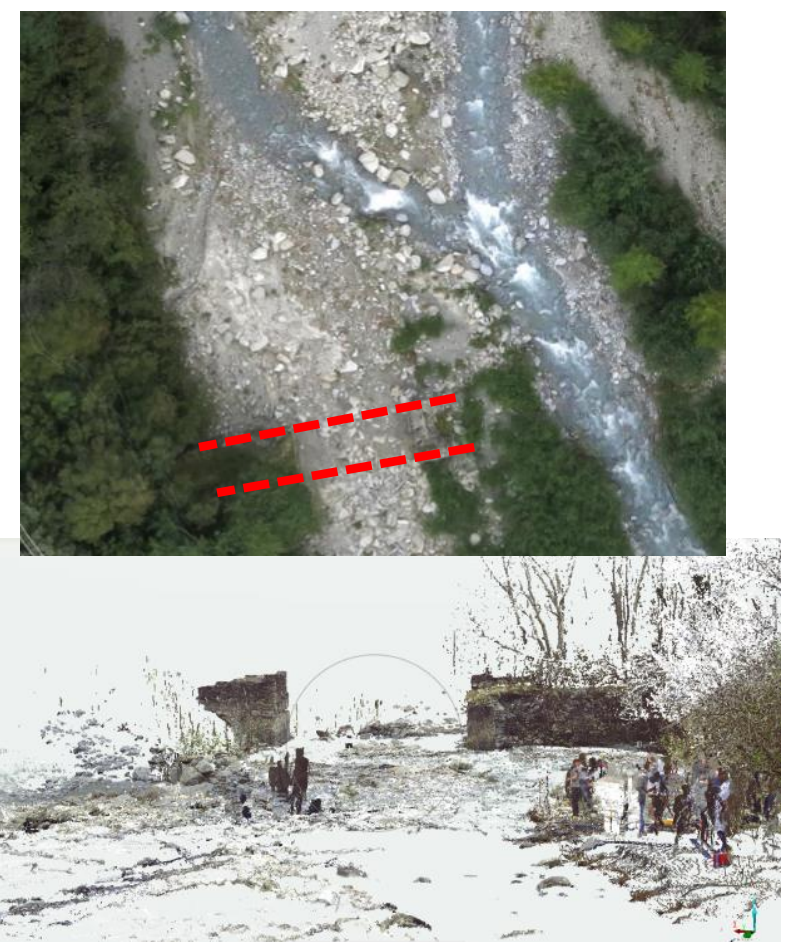

Figure 5. The ancient collapsed bridge, (above) an excerpt from the orthophoto and (below) a view of five scans registered cloud

while the y profiles were 100 , spaced $0.5 \mathrm{~m}$ and $20 \mathrm{~m}$ long. The trace duration was $150 \mathrm{~ns}$ with a sampling rate of about $6.8 \mathrm{GHz}$. On average, along $\mathrm{x}$ and $\mathrm{y}$, the interval between the radar traces was $6 \mathrm{~cm}$. After a standard processing (Sambuelli et al., 2014) the timeslices were extracted and the images on the $x-y$ plane were placed after the GPS data collected during the acquisition.
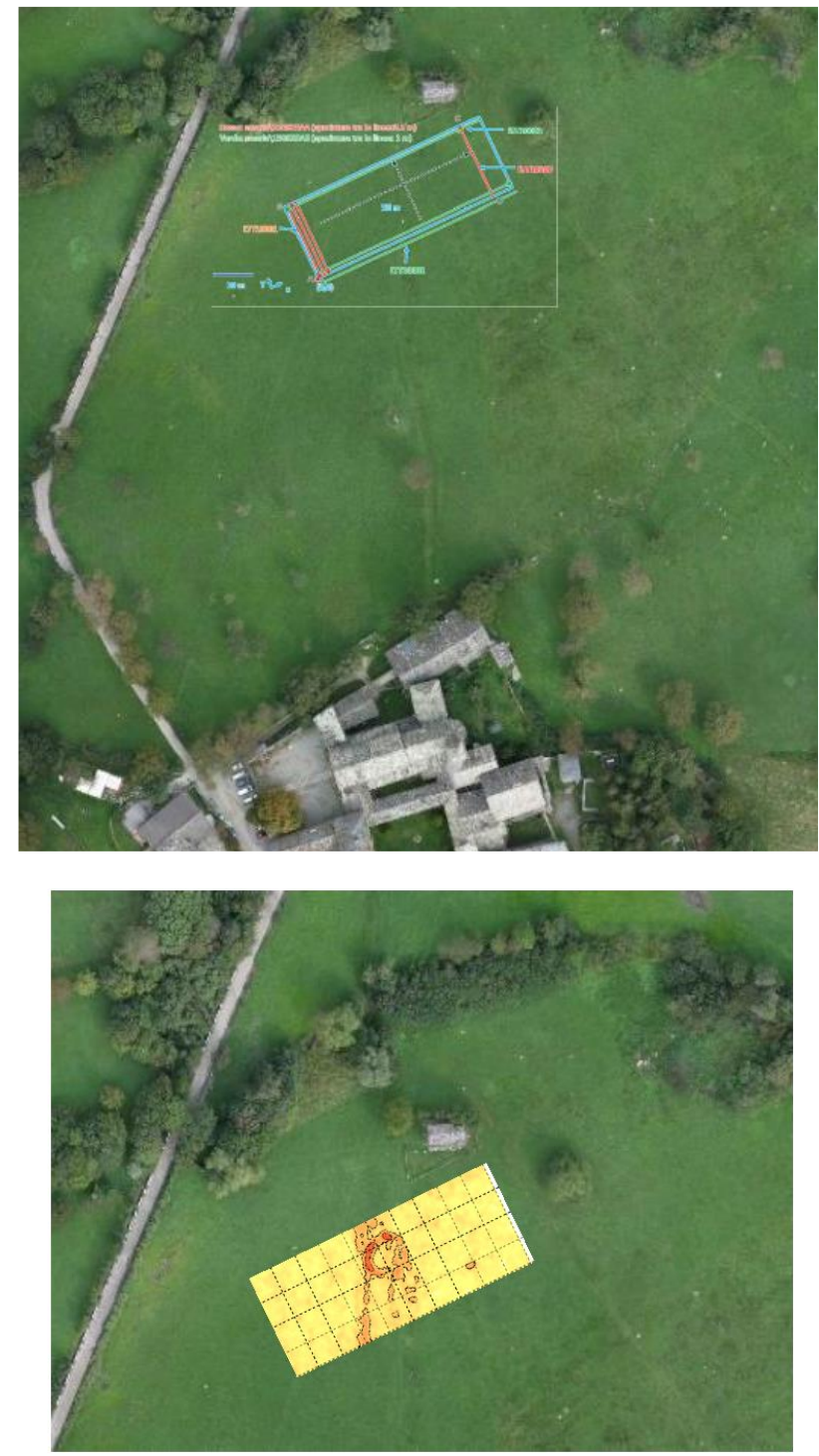

Figure 5. (Above) GPR profiles planning, topographically located onto the orthophoto. (Below) Superimposition of timeslice at $0.7 \mathrm{~m}$ of depth on orthophoto, with main anomalies derived from geophisical prospections highlighted.

Among the extracted timeslices the most significant seems the one corresponding to a depth of about $0.7 \mathrm{~m}$ (calculated according to an estimated propagation velocity of $15 \mathrm{~cm} / \mathrm{ns}$ ). At this depth, aside the trace of the ancient pathway, a plan of a round-like structure is quite clearly shown.

\subsubsection{Results}

In Novalesa project, no material source reported the presence of built structures near the entrance area of the abbey, and documentary sources refer to the passage of carriages on a bridge, which has been identified and then scanned, since today it is collapsed and disused. Many insights predicted the hypothesis concerning a possible welcoming area; therefore, in this place we localized the GPR surveys that identified submerged structures to a compatible depth. Such buried structures were not yet known to the literature of the field. 


\subsection{Second case study: Valperga castle (Piedmont - Italy)}

The town's urban conformation of Valperga complaint formation around a defensive core. The town is in fact developed at the foot of the hill on which stands the castle and is configured as a type of centralized settlement, divided into three neighborhoods.

The history of Valperga is identical with that of the Valperga family, which for several centuries has extended the control to much of the Canavese area.

It is difficult to reconstruct the history of the castle also because the spread in the sixteenth century of false documentation by the lords who wanted to affirm the exercise of power by any means. (Sergi, 1995). ${ }^{1}$

\subsubsection{Suggestions from historical iconography}

The events concerning the castle are alternate during the long centuries of struggle for control of territory and hardly reconstructable; the first track configuration similar to the present one has in cartography and drawings conserved in the "Archivio di Stato" of Turin (AST) and in the "Archivio Storico del Castello" of Masino (ASCM), dated later the half of the sixteenth century.

It is not our intention in this work retrace the history of the transformations that have given rise to the current highly stratified configuration in time of the castle, but just with the spirit of 4Dilan project, we chose to try to shed light on an aspect not investigated by historical literature.

At the beginning of the nineteenth century, some demolition and restoration of portions of the so-called Thones block has been provided. Some preserved planning drawings show the existence of a body of the building, represented as projection on the ground floor plan, so probably was aerial, which now no longer exists and that could be the cause also of the problems of static stability of the towers (figure 6). The subsequent investigations aim to clarify just these parts of the building and the tower.

\subsubsection{Image and range based integrated surveys}

Since the castle is located on the top of the hill with few open spaces available, it was decided to carry out the overall map of the castle using a vertical take-off drone.

Obviously, this carrier, offering the opportunity to acquire nadiral and oblique images is definitely much more suitable for the need to resume the buildings of the castle complex, arranged articulately and with very narrow courtyards.
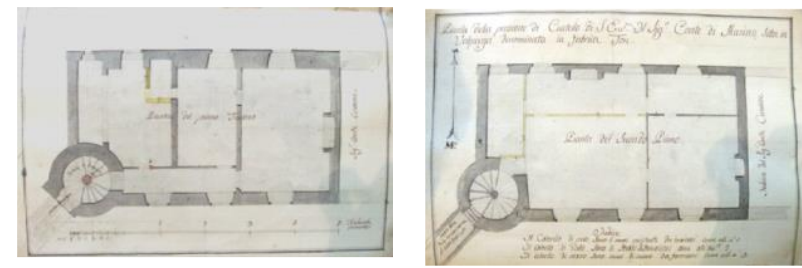

Figure 6. Pianta della prosione di Castello [...], 1807. ASCM, faldone $375 / \mathrm{n}^{\circ} 6637$.

1 The Valperga Castle was the subject of a thesis in 2010 (Cerutti, 2010), and during these months, the following students, who took part to the field and laboratory phases, are preparing other Msc theses: Nany Alejandra Matamoros Torres, Vivian Camila Pinzon Mejia, Julian David Chavez Rodriguez. All of them joined the 4Dilan project.

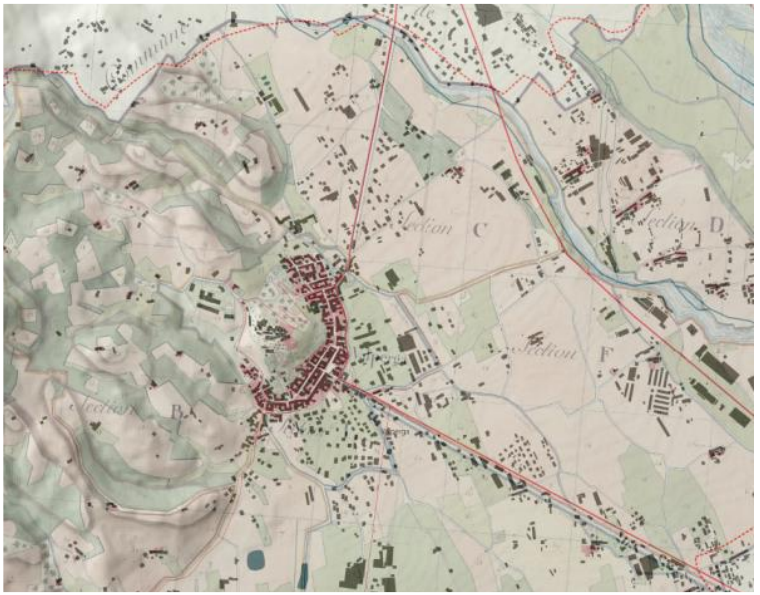

Figure 7. The sheet of Cadastral France map concerning the Valperga municipality (a multi parameters transformation providing a spatial reference to the French map has been applied in GIS environment - Nany Matamoros elaboration)

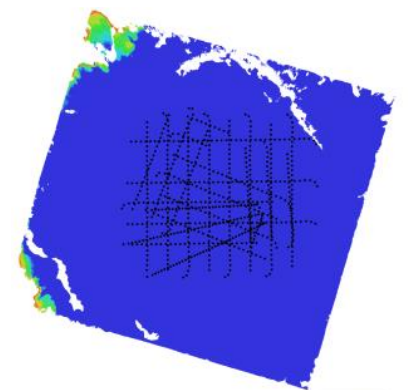

Figure 8. Automated scheme of overlapping stripes and images.

\begin{tabular}{|l|l|}
\hline camera: & Sony ILCE-5100 \\
\hline number of acquired images: & 919 \\
\hline image dimension & 6000 [pixels] x 4000 [pixels] \\
\hline pixel dimension & $4 \times 4[\mu \mathrm{m}]$ \\
\hline Ground sampling distance & $2.06[\mathrm{~cm}]$ \\
\hline focal distance: & $20[\mathrm{~mm}]$ \\
\hline flight height (medium) & $117[\mathrm{~m}]$ \\
\hline $\begin{array}{l}\text { RMS error (Root Mean } \\
\text { Square error): }\end{array}$ & $0.026[\mathrm{~m}]$ \\
\hline
\end{tabular}

Table 2 - Camera and UBIK DIATI MK01 flight parameters

The drone used is the Ubik DIATI MK01: flight planning has provided two sets of strips perpendicular to each other in northsouth direction with footage of nadiral frames, other two sets of perpendicular strips favourable to the prevailing orientation of the castle buildings with oblique shots, and a last swipe with converging streaks.

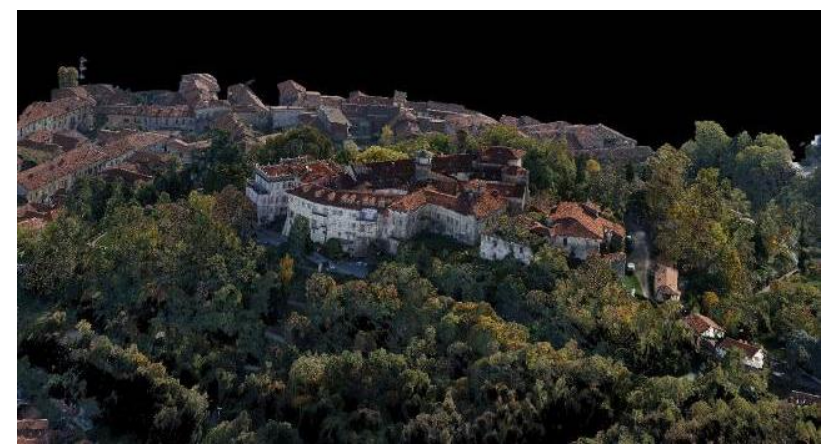




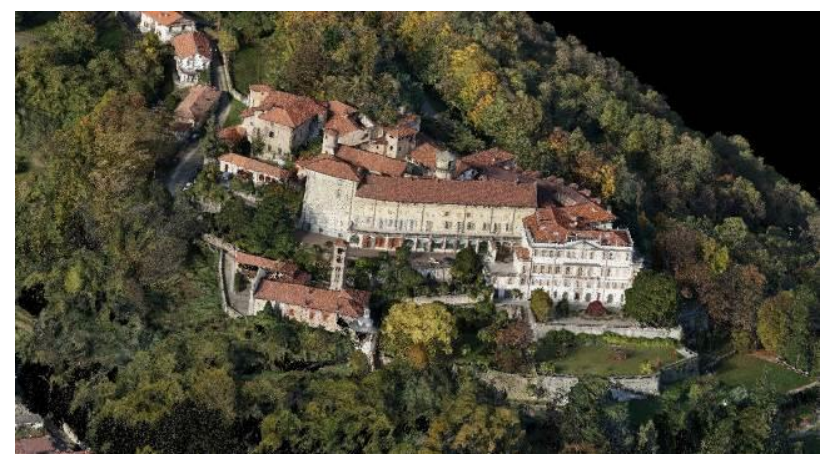

Figure 9. Two different bird eye views of the processed dense cloud. (18 milion points)
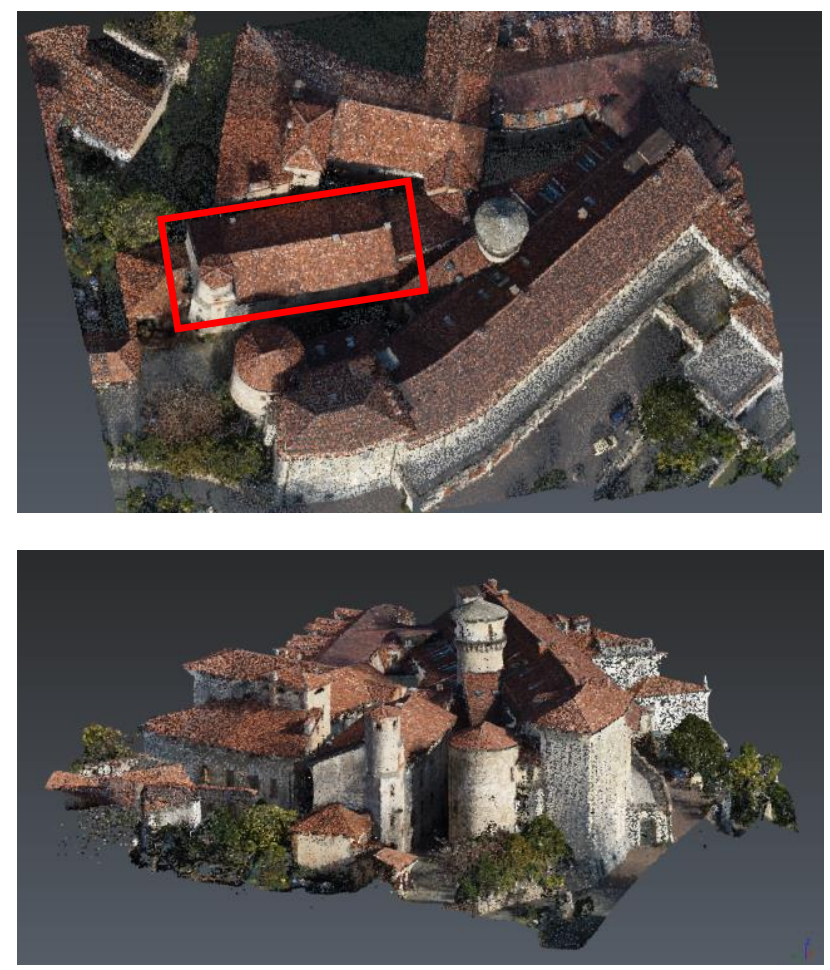

Figure 10. Other two views of an excerpt of the colored cloud; $0.026 \mathrm{~m}$ RMSE on GCP shows a good ability to represent the dense edification.

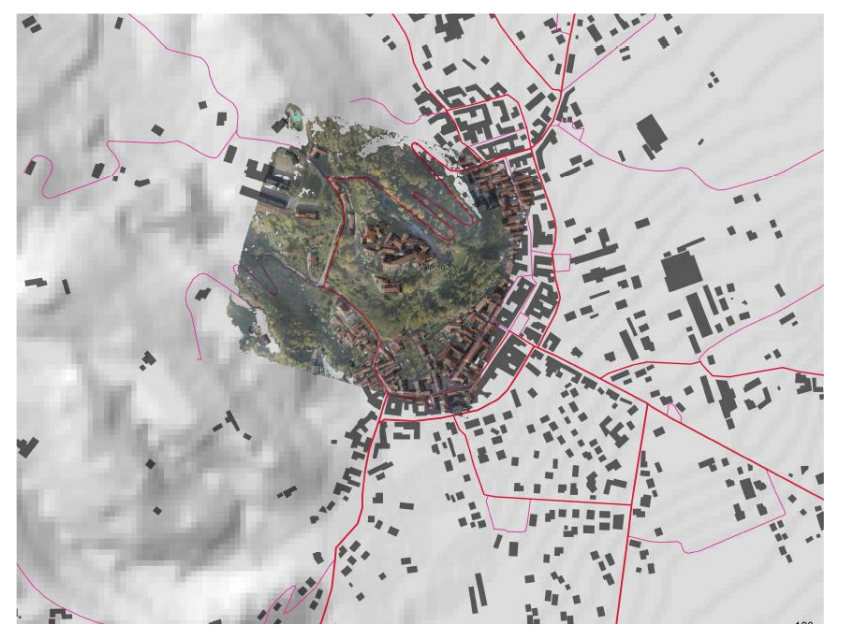

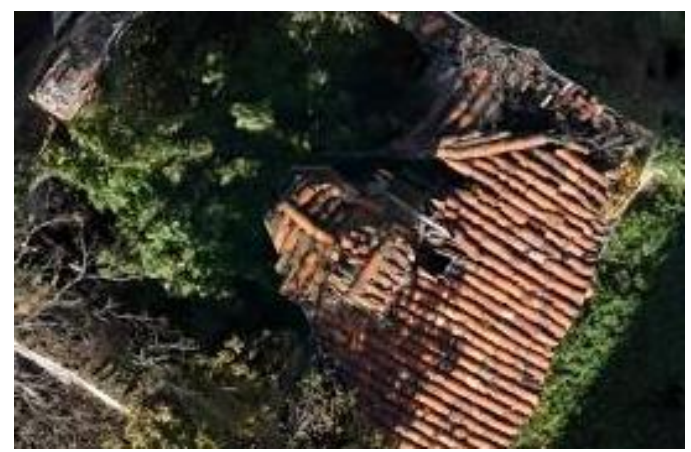

Figure 11. (side column) The $0.212 \mathrm{~km}^{2}$ extension of the orthophoto covering area, projected on regional DEM. (Nany Matamoros elab.); (above) An excerpt of the $2 \mathrm{~cm}$ resolution orthophoto, enabling to examine a collapsed roof.

The Thones building (see red box in figure 10), located between two very narrow courtyards has been surveyed with terrestrial Lidar technique, with many difficulties. The designed topographic network, which expected the determination of two vertices in the yard that border the structure to the north side, has provided an accuracy totally inadequate in the calculation of the position of the vertices.

So, the clouds from terrestrial scans were recorded by organizing the registration into three blocks (Figures 12); the first block (blue) was georeferenced through a series of targets measured by total station, while the other two blocks have been registered to the first using the shape alignment strategy.

A last phase of the test was very interesting for us since we acquired a number of laser clouds using the hand-held ZebRevo system; the clouds have been acquired by means of the closed paths strategy in order to control the closing error and they showed a good quality especially for indoor environments.

The last image of the figure 12 shows a facade of Thones building facing the South courtyard; this portion of the point model acquired through traditional terrestrial scans (Faro Focus 3D scanner) has been used as a ground truth for the ZebRevo clouds alignment. The referencing of these low-resolution clouds has been in fact processed using again the best-fit strategy.

Figure 13 shows the results of the union 4 clouds acquired with the ZebRevo system (the courtyard cloud, the underground icehouse, the basement floor and the mezzanine floor); all these best-fit alignments have provided rather satisfactory results, reaching $5 \div 6 \mathrm{~cm}$ of average error.

The interesting section profiles of Figure 14 show the relations between the UAV cloud (roof), the Lidar cloud representing buildings and courtyards and ZebRevo cloud pertaining interiors. Finally, the figure 15 shows the accuracy of a ZebRevo cloud concerning a façade sample compared with Lidar cloud.

Depending on type of surveyed surface, there are errors near to $1 \div 2 \mathrm{~cm}$ for plane surface, $5 \div 7 \mathrm{~cm}$ for distant or articulated surfaces.

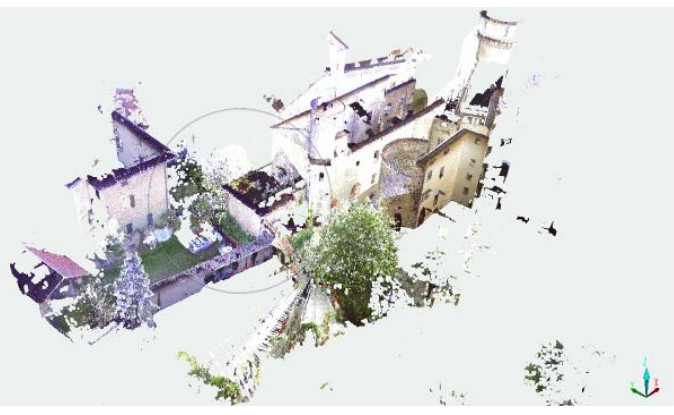




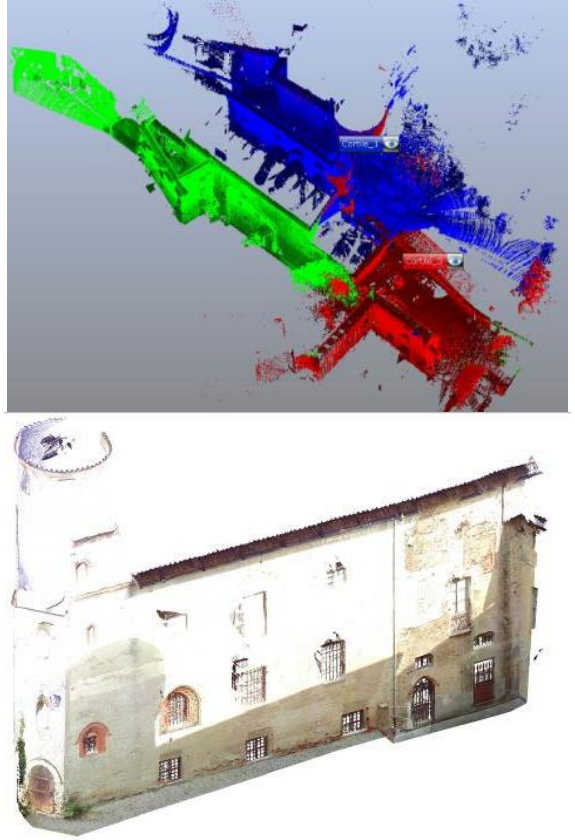

Figure 12 . (last page) the coloured Lidar Cloud of the test area. (above) the three block of clouds used for registration (below), the LiDAR model used for next comparison.

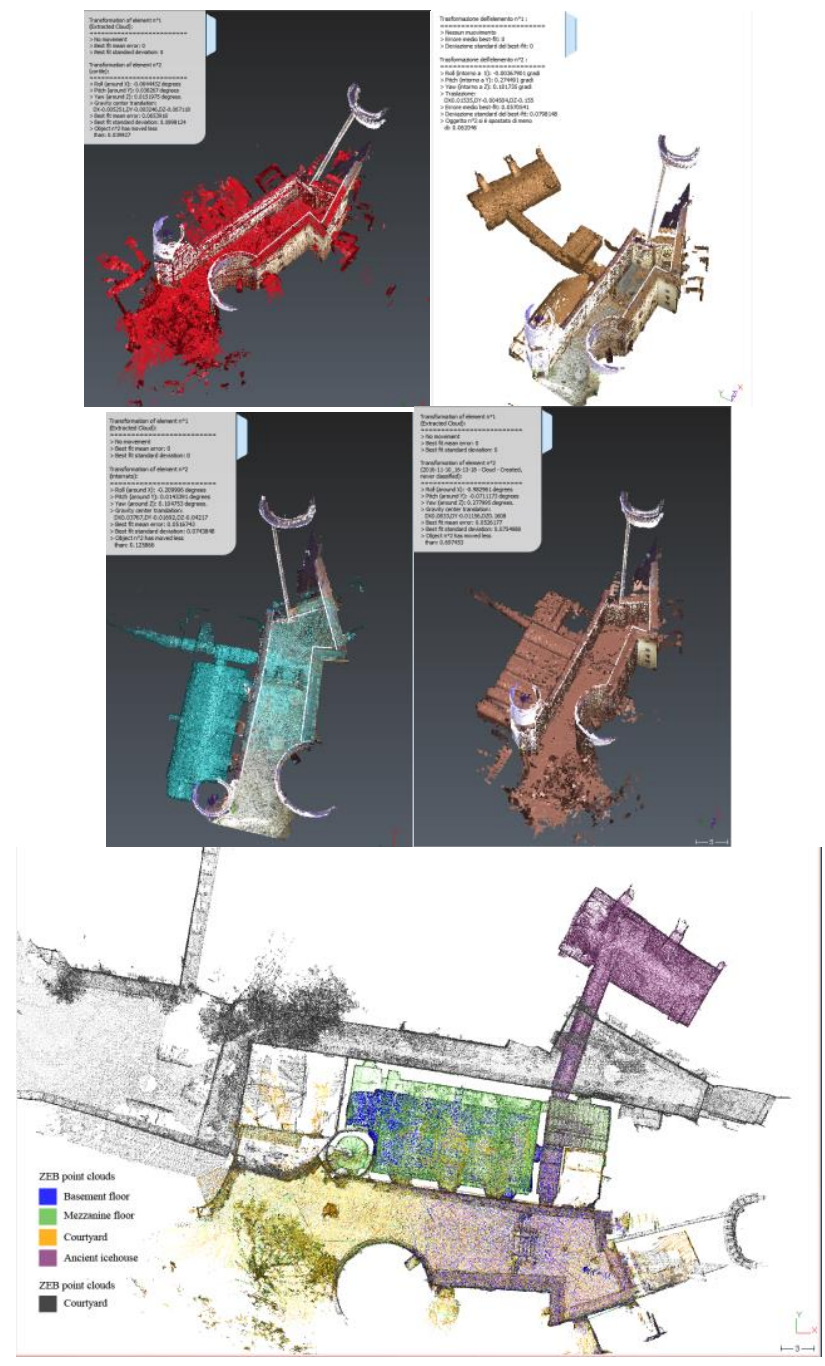

Figure 13. The ZebRevo clouds aligned by a best fit registration.

\begin{tabular}{|l|rrrr|}
\cline { 2 - 5 } \multicolumn{1}{c|}{} & \multicolumn{4}{c|}{ ZEB alignment quality with LiDAR scans (m) } \\
\cline { 2 - 6 } \multicolumn{1}{c|}{} & courtyard & ancient & basement & mezzanine \\
\multicolumn{1}{c|}{ icehouse } & floor & floor \\
\hline mean error & 0,0654 & 0,0571 & 0,0517 & 0,0526 \\
st.dev. & 0,0898 & 0,0798 & 0,0744 & 0,0755 \\
\hline
\end{tabular}

Table 3. Results of ZebRevo clouds registration.

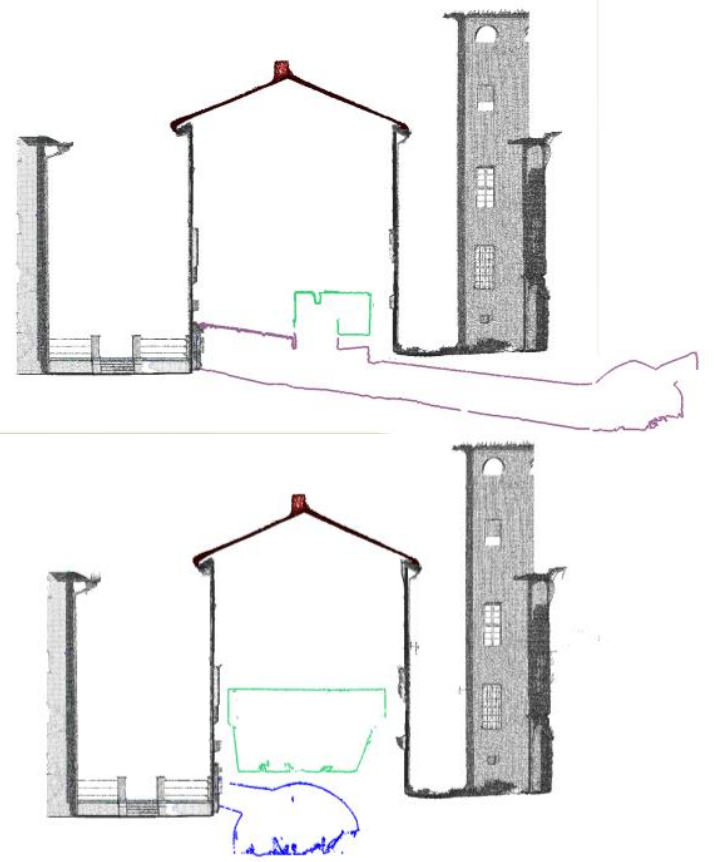

Figure 14. Section profile on UAV, LiDAR and ZebRevo clouds.

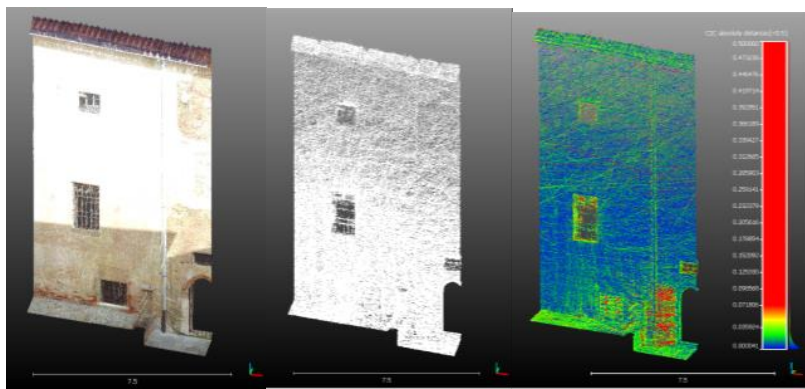

Figure 15. Comparing ZebRevo cloud to the LiDAR cloud. $(1 \div 2 \mathrm{~cm}$ for plane surface, $5 \div 7 \mathrm{~cm}$ for distant or articulated surfaces $)$

\subsubsection{GPR investigations near the tower}

The survey was made on November 10, 2016 with a K2 IDS GPR, a $200 \mathrm{MHz}$ IDS antenna and a $500 \mathrm{MHz}$ GSSI antenna. With both the antennas, the GPR profiles were acquired along the direction $\mathrm{N} 78^{\circ} \mathrm{E}$. The profiles were 21 , spaced $0.2 \mathrm{~m}$ and 12 $\mathrm{m}$ long. The trace duration was $200 \mathrm{~ns}$ with a sampling rate of about $10.2 \mathrm{GHz}$. On average the interval between the radar traces was $3 \mathrm{~cm}$. After a standard processing (Sambuelli et al., 2014) the timeslices were extracted and the images on the $x-y$ plane were placed after the GPS data collected during the acquisition.

Among the extracted timeslices the most significant seems the one corresponding to a depth of about $0.75 \mathrm{~m}$ (calculated according to an estimated propagation velocity of $12 \mathrm{~cm} / \mathrm{ns}$ ). At this depth, southward the trace of the pipe, which is the dominant structure, a plan of a rectangular structure seems to reflect some energy. 


\subsubsection{RESULTS}

In Valperga test, the process of analysis has been inverse compared with Novalesa, since the written sources report the presence of no longer visible structures, we have placed the result of the integration techniques to hypothesize and reconstruct the original layout of a tower. The data acquisition strategies, processing steps and analysis are reported in the paper with a first evaluation of the proposed approach and the final achieved results.

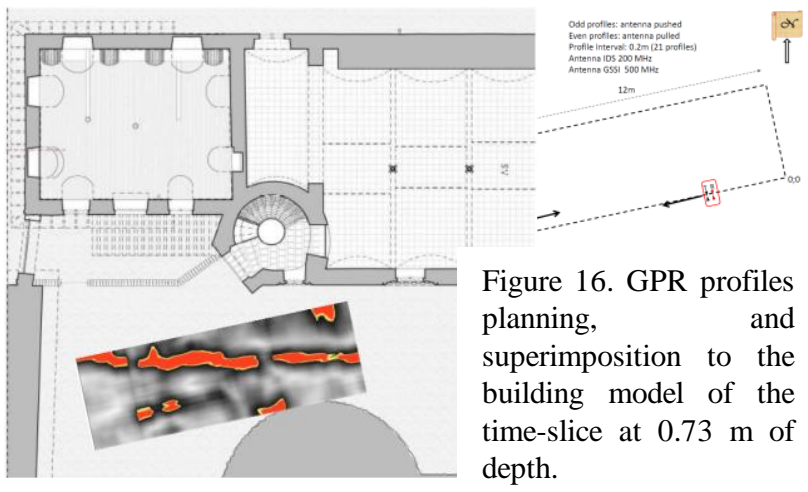

\section{DISCUSSION AND PERSPECTIVES}

Either studies are fully configured as potential anchors of plurality, wealth and stratification of the monumental, historical and artistic evidences. The 4dilan project represents a first support for connecting with tangible and intangible links, cultural systems that put in contact the fragmented parts of the historical territory. The common threads are made of an extensive georeferenced documentations through the integration of threedimensional models generated by UAV and terrestrial photogrammetry combined with Terrestrial Laser Scanner (TLS) acquisitions. What has distinguished the later stages was the way to use the written and material sources and further use of nondestructive diagnostic investigations.

\section{ACKNOWLEDGEMENTS}

The authors would like to especially thank Team Direct (https://www.facebook.com/Team-Direct-461829537253316) and all people involved in the data acquisition, including Andrea Lingua, Paolo Maschio and Diego Franco from Politecnico di Torino for the operative phase on Novalesa test. We thank furthermore Politecnico di Torino for promoting and financing the student project 4Dilan.

\section{REFERENCES}

Aicardi, I., Chiabrando, F., Grasso, N., Lingua, A. M., Noardo, F., Spanò, A., 2016. UAV photogrammetry with oblique images: first analysis on data acquisition and processing, ISPRS Archives, XLI-B1, 835-842, doi:10.5194/isprs-archives-XLI-B1-835-2016, 2016.

Alsadik, Bashar, 2016, Crowdsource and web-published videos for 3D documentation of cultural heritage objects", Journal of Cultural Heritage, 25.4, 899-903.

Arato, A., Garofalo, F., Sammartano, G, Spanò, A., 2016, Gathering GPR inspections and UAV survey in Cultural Heritage documentation context, in proceedings of the International GISTAM Conference, Rome. 85-91

Brogiolo G. P., Cagnana A., 2012. Archeologia dell'architettura metodi e interpretazioni, All'insegna del Giglio, Firenze.
Bosse M., Zlot R., Flick P., 2012, Zebedee: Design of a SpringMounted 3D Range Sensor with Application to Mobile Mapping, IEEE Transactions on Robotics, 28 (5), 1104 - 1119, DOI:10.1109/TRO.2012.2200990.

Cerutti, E, 2010. Il castello di Valperga. Analisi delle trasformazioni architettoniche dal XVI al XIX secolo. Thesis, tutor: C. Cuneo.

Chiabrando F., Sammartano G., Spanò A., Teppati Losè L., 2017. UAV oblique photogrammetry and lidar data acquisition for $3 \mathrm{~d}$ documentation of the Hercules fountain, in VAR, 2017.

Cohen A., Sattler T., Pollefeys M., 2015, Merging the unmatchable: stitching visually disconnected SfM Models, ICCV.

Davis, J.L., Annan, A.P., 1989. Ground-penetrating radar for high resolution mapping of soil and rock stratigraphy. Geophysical Prospecting 37, 531-551.

Harris E.C., 1989. Principles of Archaeological Stratigraphy. Academic Press; $2^{\text {nd }}$ edition (Jun 15, 1989).

Lerma, J. L., Seguí, A. E., Cabrelles, M., Haddad, N., Navarro, S., Akasheh, T., 2011. Integration of laser scanning and imagery for photorealistic 3D architectural documentation. INTECH Open Access Publisher. DOI: 10.5772/14534.

Patrucco, G., 2016. Tecniche innovative UAV e LiDAR per l'analisi stratigrafica delle murature: il chiostro dell'abbazia di Novalesa. Msc thesis, tutors Spanò, Chiabrando, Naretto.

Reynolds, J.M., 1997. An Introduction to Applied and Environmental Geophysics. John Wiley \& Sons, NY.

Remondino, F., Barazzetti, L., Nex, F., Scaioni, M., Sarazzi, D. 2011. UAV photogrammetry for mapping and 3D modeling-current status and future perspectives. ISPRS Archives, 38(1), C22. DOI: 10.5194/isprsarchives-XXXVIII-1-C22-25-2011

Riisgaard S., Blas M., 2005. Slam for Dummies. A Tutorial Approach to Simultaneous Localization and Mapping, Available: http://ocw.mit.edu/NR/rdonlyres/Aeronautics-and-Astronautics/16412JSpring-2005/9D8DB59F-24EC-4B75-BA7AF0916BAB2440/0/1aslam-blas-repo.pdf.

Sambuelli, L., Böhm, G., Colombero, C., Filipello, A., 2015. Photogrammetry and 3-D Ultrasonic Tomography to Estimate the Integrity of Two Sculptures of the Egyptian Museum of Turin. In: Near Surface Geoscience 2015 - 21st European Meeting of Environmental and Engineering Geophysics, doi: 10.3997/22144609.201413675

Sambuelli L., Elia D., Meirano V., Colombero C., 2014. Case history: a magnetic and GPR prospection on a Roman rural villa in western Piedmont (Italy), in: $33^{\circ}$ Conv. Naz. Gruppo Nazionale di Geofisica della Terra Solida, Bologna, 25-27 Nov. 2014. 191-195

Sergi, G., 1995. I confini del potere. Marche e signorie fra due regni medioeval, Einaudi, Torino, 195.

Stathopoulou, E. K., Georgopoulos A., Panagiotopoulos G., Kaliampakos D., 2015, Crowdsourcing Lost Cultural Heritage. ISPRS Annals of ISPRS, Vol. II-5/W3, 295-300

Wiedemann, A., More, J. (2012). Orientation strategies for aerial oblique images. ISPRS Archives, Vol. 39 (B1). DOI: 10.5194/isprsarchives-XXXIX-B1-185-2012 